\title{
Review Article \\ Cellular Senescence as a Target in Cancer Control
}

\author{
Mar Vergel, ${ }^{1}$ Juan J. Marin, ${ }^{2}$ Purificacion Estevez, ${ }^{1}$ and Amancio Carnero ${ }^{1,3}$ \\ ${ }^{1}$ Instituto de Biomedicina de Sevilla, Hospital Universitario virgen del Rocio, 41013 Sevilla, Spain \\ ${ }^{2}$ Department of Preventive Medicine and Public Heath, University of Seville, 41012 Seville, Spain \\ ${ }^{3}$ Consejo Superior de Investigaciones Cientificas, Avenida Manuel Siurot s/n, 41013 Sevilla, Spain \\ Correspondence should be addressed to Amancio Carnero, acarnero@ibis-sevilla.es
}

Received 27 September 2010; Accepted 3 November 2010

Academic Editor: Matilde E. LLeonart

Copyright ( $) 2011$ Mar Vergel et al. This is an open access article distributed under the Creative Commons Attribution License, which permits unrestricted use, distribution, and reproduction in any medium, provided the original work is properly cited.

\begin{abstract}
Somatic cells show a spontaneous decline in growth rate in continuous culture. This is not related to elapsed time but to an increasing number of population doublings, eventually terminating in a quiescent but viable state termed replicative senescence. These cells are commonly multinucleated and do not respond to mitogens or apoptotic stimuli. Cells displaying characteristics of senescent cells can also be observed in response to other stimuli, such as oncogenic stress, DNA damage, or cytotoxic drugs and have been reported to be found in vivo. Most tumors show unlimited replicative potential, leading to the hypothesis that cellular senescence is a natural antitumor program. Recent findings suggest that cellular senescence is a natural mechanism to prevent undesired oncogenic stress in somatic cells that has been lost in malignant tumors. Given that the ultimate goal of cancer research is to find the definitive cure for as many tumor types as possible, exploration of cellular senescence to drive towards antitumor therapies may decisively influence the outcome of new drugs. In the present paper, we will review the potential of cellular senescence to be used as target for anticancer therapy.
\end{abstract}

\section{The Biology of Senescence}

Over 40 years ago, Hayflick [1] established that human diploid fibroblasts show a spontaneous decline in growth rate in continuous culture related not to elapsed time but to an increasing number of population doublings, eventually terminating in a quiescent but viable state now known as replicative senescence. These cells show a flat, enlarged morphology with low $\mathrm{pH} \beta$-gal activity, are commonly multinucleated, and are irresponsive to mitogens or apoptotic stimuli. Similar behaviour has since then been observed in a wide variety of normal cells, and it is now widely accepted [2] that normal human somatic cells have an intrinsically limited proliferative lifespan, even under ideal growth conditions. Moreover, the senescent phenotype is associated with a typical gene-expression profile [3-5]. Cells displaying characteristics of senescent cells, however, can be observed in response to other stimuli, such as oncogenic stress, DNA damage, or cytotoxic drugs [6].

Cells displaying senescent characteristics have not only been observed in cell culture but also in their maternal tissue environment. A number of reports have related reduced cellular lifespan with metabolic disease, stress sensitivity, progeria syndromes, and impaired healing, indicating that entry into cellular senescence may contribute to human disease. Indeed, it has been suggested that cellular senescence is in part responsible for the pathogenesis of a number of human diseases, such as atherosclerosis, osteoarthritis, muscular degeneration, ulcer formation, Alzheimer's dementia, diabetes, and immune exhaustion.

Most cancers contain cell populations that have escaped the normal limitations on proliferative potential. This capability, known as immortality, contrasts with the limited lifespan of normal somatic cells. It has therefore been proposed that cellular senescence is a major tumor suppressor mechanism that must be overcome during tumorigenesis [2].

The kinetics of replicative senescence do not show an abrupt arrest of the whole population, but a gradual decline in the proportion of dividing cells [7], the exact timing of which varies between both cell types and sister clones [8]. This behaviour is best explained as the result of (i) an intrinsic control mechanism linked to elapsed cell divisions-the senescence clock-which progressively desensitises the cellcycle machinery to growth factor stimulation, together with 
(ii) a stochastic component probably having the same (still unknown) basis as that observed in immortal cells under conditions of growth factor restriction. Stem cells can give rise to differentiated progeny and are capable of autorenewal. In some renewing tissues, stem cells undergo more than 1000 divisions in a lifetime with no morphological signs of senescence [8]. This indicates that at a certain point of lineage differentiation, cells activate the senescence clock that ultimately induces cell senescence through a series of effectors.

More recently, the finite number of divisions-referred to as the "Hayflick limit" - was attributed to the progressive shortening of chromosomal ends. Telomere shortening is considered to be the most probable molecular mechanism explaining the existence of such a senescence clock controlling replicative senescence $[9,10]$. Eukaryotic cells cannot replicate the very ends of their chromosomes, the telomeres, resulting in shortening their lengths with every cell division until they reach a critical threshold, at which point cells stop replicating [11]. However, enforced replication despite short telomeres ends in high chromosomal instability and apoptosis, a process known as crisis. Many other mechanisms, however, have been also proposed (Table 1).

Senescent cells display molecular markers characteristics of cells bearing double-strand breaks. These markers include nuclear foci of phosphorylated histone H2AX and the localization at double-strand break sites of DNA-repair and DNA-damage checkpoint factors, such as 53BP1, MDC1, and NBS1 $[12,13]$. Senescent cells also contain activated forms of the DNA-damage checkpoint kinases Chk1 and Chk2. These and other results suggest that telomere shortening initiates senescence trough a DNA-damage response. This will explain why other DNA-damaging stresses, such as culture shock, might initiate senescence without telomere involvement. The initiation of senescence triggers the generation and accumulation of distinct heterochromatic structures known as senescence associated heterochromatic foci (SAHF). The formation of SAHF coincides with the recruitment of heterochromatic proteins and the $\mathrm{pRB}$ tumor suppressor to E2F-responsive promoters. SAHF accumulation is associated with stable repression of E2F target genes and does not occur in reversibly arrested cells. SAHF formation and promoter repression depend on the integrity of the $\mathrm{pRb}$ pathway [14]. These results provide an explanation for the stability of the senescent state.

Consistent with a role in aging, senescent cells accumulate with age in many rodent and human tissues [15]. Moreover, they are found at sites of age-related pathology, including degenerative disorders such as osteoarthritis and atherosclerosis [15] and hyperproliferative lesions such as benign prostatic hyperplasia [16] and melanocytic naevi [17]. A limited number of cell culture and mouse xenograft studies support the idea that senescent cells secrete factors that can disrupt tissue structure and function and promote cancer progression [18-20]. Recent studies on the senescence-associated secretory phenotype (SASP) of human and mouse fibroblasts show that it is conserved across cell types and species and that specific secreted factors are strong candidates for stimulating malignant phenotypes in neighboring cells [21-23].
The idea that a biological process such as cellular senescence can be both beneficial (tumor suppressive) and deleterious (protumorigenic) is consistent with a major evolutionary theory of aging termed antagonistic pleiotropy [23]. The SASP may be the major reason for the deleterious side of the senescence response [24].

In addition to telomere dysfunction, cellular senescence can be elicited by other types of stress, including oncogene activation [25]. This phenomenon is not observed for oncogenic RAS exclusively; many-but not all—of its effectors, including activated mutants of RAF, MEK, and BRAF, were shown to cause senescence as well [26-29]. Some oncogenes, such as RAS, CDC6, cyclin E, and STAT5 which induce senescence also trigger a DNA-damage response (DDR), which is associated with DNA hyperreplication and appears to be causally involved in oncogene-induced senescence (OIS), in vitro [30-33]. During most of the last decade, OIS has been studied predominantly in cell culture systems, triggering a long debate as to whether or not OIS corresponds to a physiologically relevant phenomenon in vivo. In favour of OIS representing an in vitro phenomenon only is that artificial conditions, such as the use of bovine serum and plastic dishes, as well as the presence of supraphysiologic O2, generate a stress signal that at the very least contributes to triggering a cellular senescence response $[34,35]$. However, conversely, senescence bypass screens have identified several genuine human oncogenes, including TBX2, BCL6, KLF4, hDRIL, BRF1, and PPP1CA [36]. Furthermore, virtually all human cancers lack functional p53/pRB pathways, two key senescence-signalling routes [37], and often carry mutations in sets of genes, which are known to collaborate in vitro in bypassing the senescence response.

\section{Effector Pathways}

Cellular senescence pathways are believed to have multiple layers of regulation, with additional redundancy built into these layers [38]. On the basis of the complementation studies, there are at least four senescence genes or pathways. There are, however, many more chromosomes that can induce senescence than there are senescence complementation groups. Furthermore, there are some immortal cell lines that have been assigned to multiple complementation groups [39]. This indicates that in any one immortal cell line, there are probably multiple senescence genes/pathways that are abrogated [40]. Many of the functional studies, where a putative senescence gene is overexpressed in cells, indicate that although multiple genes/pathways may be abrogated in a particular cell line, as little as one gene/pathway is required for repair and subsequent reversion to senescence.

Pathways known to regulate cellular senescence/immortalisation, including the $\mathrm{p} 16 \mathrm{INK} 4 \mathrm{a} / \mathrm{pRB}$ pathway, the p19ARF/p53/p21CIP1/WAF1 pathway, and the PTEN/ p27KIP1 pathway, are reviewed in [36, 41-44]. Other genes that have been shown to induce a senescence-like phenotype include PPP1A [45], SAHH [46, 47], Csn2, Arase and BRF1 [48], PGM [49], IGFBP3 and IGFBPrP1 [50], PAI-1 [51, 52], MKK3 [53], MKK6 [53, 54], Smurf2 [55], and HIC-5 [56]. All these genes have shown to be related to human 
TABLE 1: Cellular clock driving senescence hypothesis.

\begin{tabular}{|c|c|c|}
\hline Cellular clock & Cause & Molecular readout \\
\hline \multicolumn{3}{|l|}{ Error-catastrophe theories } \\
\hline Somatic mutation accumulation & Metabolism/oxygen free radicals & Altered protein function, DNA damage \\
\hline Mitochondrial DNA mutation & Oxygen free radicals & Altered mitochondrial function \\
\hline Posttranslational modification of proteins & $\begin{array}{l}\text { Oxidation, glycosylation, acetylation, } \\
\text { methylation, and so forth }\end{array}$ & Altered function of proteins \\
\hline Altered proteolysis & Errors in proteolysis machinery & Accumulation non functional proteins \\
\hline \multicolumn{3}{|l|}{ Deterministic theories } \\
\hline Telomere shortening & no replication of the telomere ends & $\begin{array}{l}\text { DNA damage, exposure ends of } \\
\text { telomeres, Liberation regulatory } \\
\text { proteins, and so forth }\end{array}$ \\
\hline Changes in heterochromatin domains & & changes in transcription \\
\hline Changes in DNA methylation & & changes in transcription \\
\hline Codon restriction & $\begin{array}{l}\text { Switching codon preferences in early } \\
\text { development, restrict availability later In life }\end{array}$ & Altered protein synthesis \\
\hline Terminal differentiation & $\begin{array}{l}\text { Senescence is a form of terminal di- } \\
\text { fferentiation genetically controlled }\end{array}$ & \\
\hline
\end{tabular}

tumorigenesis. However, all these genes and their pathways, as indicated earlier, can act in sequential steps conforming a well-regulated process.

Two major effector pathways have been directly related to senescence: the $\mathrm{p} 14 \mathrm{ARF} / \mathrm{p} 53 / \mathrm{p} 21$ pathway and the INK4/CDK/pRb pathway [57] (Figure 1). The absence of $\mathrm{p} 53$ function induced by dominant negative mutants, specific p53 antisense mRNA, oligonucleotides, or viral oncoproteins (such as SV40 T antigen or HPV16 E6) is sufficient to substantially extend the lifespan of several cell types in culture [58]. Consistent with this, senescence is associated with a switch-on of the transactivation function of p53 in culture [59]. Coincident with telomere shortening, DNA-damage checkpoint activation, and associated genomic instability, p53 is also activated in vivo[60]. Deletion of p53 attenuated the cellular and organismal effects of telomere dysfunction, establishing a key role for p53 in the shortening response [60].

Other p53 regulatory proteins are also involved in senescence (Figure 1). MDM2 protein has p53 ubiquitin ligase activity and forms an autoregulatory loop with p53 [61]. Overexpression of MDM2 targets p53 for degradation and induces functional-p53 loss [62]. The product of another gene upregulated in senescence-p14ARF-can release p53 from inhibition by MDM2 and cause growth arrest in young fibroblasts [62]. Seeding mouse embryonic fibroblasts (MEFs) into culture induces the synthesis of ARF protein, which continues to accumulate until the cells enter senescence [63]. MEFs derived from ARF-disrupted mice [63] or wild-type fibroblasts expressing an efficient ARF antisense construct [64] are also efficiently immortalised. Concomitant with this observation, overexpression of MDM2 in naïve MEFs produces efficient immortalisation [64].
Activation of p53 induces the upregulation of the cyclindependent kinase (CDK) inhibitor p21WAF1, which has a direct inhibitory action on the cell-cycle machinery [37] and correlates well with the declining growth rate in senescing cultures. In mouse embryo fibroblasts, however, the absence of p21WAF1 does not overcome senescence $[65,66]$. This suggests that at least one additional downstream effector is needed for p53-induced growth arrest in senescence. In contrast, a different behaviour is observed in human cells, where elimination of p 21 by a double round of homologous recombination is sufficient to bypass senescence [67]. Other p53 effectors might be also involved, such as 14-3-3 and GADD45, which inhibit G2/M transition or downregulation of Myc [68] (Leal and Carnero, Unpublished results).

The retinoblastoma tumor suppressor pathway, $\mathrm{pRb}$, has also been related to senescence (Figure 1). Overexpression of $\mathrm{pRb}$, as well as some of the regulators of the $\mathrm{pRb}$ pathway such as CDK inhibitors, leads to growth arrest mimicking the senescent phenotype [26]. Moreover, inactivation of $\mathrm{pRb}$ by viral oncoproteins such as E7, SV40 large T antigen, and E1A leads to extension of lifespan [69-71]. Other members of the pocket protein family comprising pRb, p130, and p107 may also be involved. In MEFs, p130 levels decrease with population doublings and MEFs from triple $\mathrm{pRb}, \mathrm{p} 130$, and p107 knockout mice are immortal [72]. Nevertheless, since a certain degree of complementation has been observed among the pocket protein family [72], it is difficult to assess the role of each protein in replicative senescence.

Given that p16INK4a functions to inhibit the inactivation of $\mathrm{pRb}$ by CDKs [73], a loss of functional p16INK4a may be expected to have similar consequences with the loss of functional $\mathrm{pRb}$. Several types of human cells accumulate p16INK4a protein as they approach senescence [74]. Senescent fibroblasts may contain p16INK4a levels at least 40-fold 


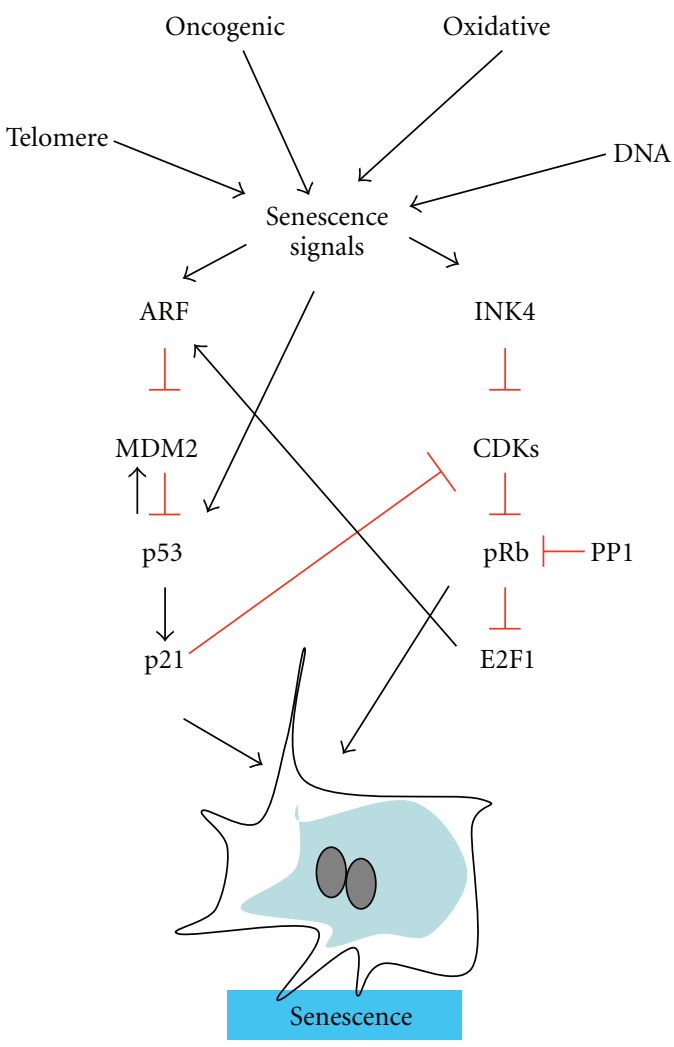

Figure 1: Scheme representing the senescence effector pathways crosstalk.

greater than early passage cells. The deletion of p16INK4a is common in immortalised tumor cell lines [75], and several nontumorigenic in vitro immortalised cell lines also lack functional p16INK4a protein. Expression of p16INK4aspecific antisense in naïve MEFs increases the probability of immortalisation of these cells [64]. In accordance with this observation, mice cells which are made nullizygous for p16INK4a by targeted deletion undergo immortalisation more readily than normal control cells $[76,77]$ although they show normal senescence kinetics. Knockout mice for p16INK4a proteins develop normally to adulthood and are fertile, indicating that the individual INK4 proteins are not essential for development. p16INK4a deficiency, however, results in a low susceptibility to spontaneous tumor development and increased tumor susceptibility under specific carcinogenic protocols [76, 77]. A crosstalk among the different pathways involved in senescence has been found. This crosstalk might ensure the correct functioning of the senescence program. Moreover, genes such as myc that are involved in all the pathways are able to bypass senescence in human primary cells. Myc can bypass CDK4/6 inhibition by activating $\mathrm{CDK} 2$-cyclinA/E complexes and inducing the Cdk-activating phosphatase Cdc25A [78]. Moreover, myc induces degradation of $\mathrm{p} 27$, thus influencing the inhibitory effects of PTEN. Finally, expression of myc induces telomerase activity by activating the transcription of the catalytic subunit [79]. The overall result is a single step immortalisation of human cells induced by myc gene amplification [80].
Over all steps, DNA methylation regulates expression of senescence genes, with the capability of controlling the process [44]. In human cancers, the silencing of tumour suppressor genes through aberrant DNA methylation of the CpG island(s) in promoters in these genes is a common epigenetic change [81]. There are an assortment of pathways from which genes have been shown to be hypermethylated in cancer cells, including DNA repair, cell-cycle control, invasion, and metastasis. The tumour suppressor genes BRCA1, p16INK4a, p15INK4b, p14ARF, p73, and APC are among those silenced by hypermethylation although the frequency of aberrant methylation is somewhat tumourtype specific. Recently, we found S-adenosylhomocysteine hydrolase (SAHH) [46], which has also been previously identified in an independent short hairpin RNA (shRNA) screening [82], the inactivation of which confers resistance to both p53- and p16(INK4)-induced proliferation arrest and senescence. SAHH catalyzes the hydrolysis of S-adenosylhomocysteine to adenosine and homocysteine. In eukaryotes, this is the major route for disposal of Sadenosylhomocysteine formed as a common product of each of the many S-adenosylmethionine-dependent methyltransferases, therefore, regulating the methylation processes. Interestingly, SAHH inactivation inhibits p53 transcriptional activity and impairs DNA-damage-induced transcription of p21(Cip1). SAHH messenger RNA (mRNA) was lost in 50\% of tumour tissues from 206 patients with different kinds of tumours in comparison with normal tissue counterparts. Moreover, SAHH protein was also affected in some colon cancers $[46,47]$.

\section{Clinical Implications}

The implication of senescence as a barrier to tumorigenesis first comes from the realisation that a limited number of duplications necessarily reduces the possibility of tumor growth. However, the proliferative lifespan before reaching the Hayflick limit could be sufficient to generate a tumor mass greater than that required for lethality. This argument fails to take into account the existence of ongoing cell death and differentiation within a tumor and the occurrence of clonal selection driven by different senescence barriers or barriers unrelated to senescence. Finally, a clinically significant cancer can be composed of entirely mortal, presenescent cells if the cell of origin has a sufficient proliferative lifespan, and the tumor develops with few successive clonal expansion steps and/or with a low cell death rate. Even with these examples, however, senescence may of course still be a significant barrier to the recurrence of tumors from the small number of residual cells remaining after therapy.

As mentioned, several studies in vivo show that oncogene-induced senescence provides a bona-fide barrier to tumorigenesis. Michaloglou and coworkers [83] have shown that an oncogenic BRaf can induce senescence in fibroblasts and melanocytes and that human nevi display markers of senescence. Therefore, sustained exposure of melanocytes to aberrant mitotic stimuli provokes senescence after an initial proliferation burst. Collado and coworkers [84] identified senescent cells in vivo after generating new 
senescence biomarkers from array studies. Using conditional Kras-val12 mice strains, they observed senescence markers to be predominant in premalignant lesions of the lung and pancreas, but not in those that have progressed to full-blown cancers. Direct evidence that hyperproliferative signals can trigger a program of permanent arrest in vivo have been provided in a transgenic model conditionally expressing E2F3 in the pituitary gland [85]. E2F3 induced hyperplasias that failed to progress because the cells became insensitive to further mitogenic signals. This insensitivity correlated with the appearance of senescence markers and a terminally arrested cellular state. Disruption of PTEN in mice also produces hyperplastic conditions analogous to prostatic intraepithelial neoplasia (a precancerous lesion in men). These lesions display senescence markers [86]. Loss of p53 prevents senescence in response to PTEN ablation and cooperates to produce invasive prostate carcinomas. These results are consistent with the notion that senescence actively limits malignant conversion.

In human fibroblasts in culture, the senescence program involves chromatin reorganisation involving $\mathrm{H} 3$ methylation at the Lys9 residue concomitant with the recruitment of heterochromatin proteins to some proliferation-related genes. Braig and coworkers [87] found that disruption of Suv39h1 methyltransferase, which methylates the Lys9 residue of $\mathrm{H} 3$, blocked ras-induced senescence and accelerated ras-induced lymphomagenesis in mice. Interestingly, Suv39h1-expressing tumors responded through senescence to chemotherapy; however, Suv39h1-null tumors did not show any senescent response but still maintained the apoptotic response. Treating ras transgenic mice with DNA-methyltransferase or histone deacetylase inhibitors, which mimic the effects of Suv39h1 disruption, accelerated ras-induced tumorigenesis.

The concept of cancer being a disease whereby cells have lost the ability to senesce leads to a critical evaluation of the benefits that can be achieved for cancer diagnosis, and therapy through the knowledge surrounding molecular pathways (both genetic and epigenetic in origin) that induce senescence. Until just a few years ago, it was accepted that tumor cells were no longer capable of senescence. Today, however, it is accepted that neoplastic cells can be forced to undergo senescence by genetic manipulations and by epigenetic factors, including anticancer drugs, radiation, and differentiating agents $[26,88]$. However, although not fully studied in vivo, it has been shown that senescent cells might increase the oncogenic potential of tumor cells. Therefore, it will be necessary to understand the contribution of senescent stromal cells to tumors, before applying druginduced senescence program to tumors.

Immortalising defects are recessive and can be blocked by imposing the process of senescence [89]. The first approach to inducing senescence to tumor cells was through somatic cell fusion. These studies identified four senescencedetermining complementation groups. In recent years, it has been found that different tumoral cell lines show cellular growth arrest along with senescence markers after the genetic expression of tumor suppressor genes commonly involved in senescence, such as p53, p21, p16, pRb, or p21 [90]. Similarly, the restoration of cellular levels of p53 in a cell line conditionally immortalised by p53 antisense expression induces growth arrest with a senescent phenotype [91]. Adenovirus vectors carrying CKIs (p16INK4a, p15INK4b, p21cip1, and p27kip1) as vehicles for delivery and expression are a powerful approach to examining therapeutic applications both in vitro and in vivo, with promising results [92]. When a 16-amino acid transmembrane carrier segment derived from the Drosophila antenappedia protein was linked to the third ankyrin repeat of the p16INK4a protein and inserted into cells, Rb-dependent $\mathrm{G}_{1}$ arrest was observed. In a breast-derived cell line, the chimera containing the antennapedia peptide and the carboxyl-terminal residue of p21waf1 had higher specificity for CDK4/cyclin D than for $\mathrm{CDK} 2 /$ cyclin $\mathrm{E}$ and arrested the cells in $\mathrm{G}_{1}$ phase [93].

These observations indicate that tumor cells maintain at least some of the components of the cellular senescence program, including terminal growth arrest. It is now clear that depending upon the cell proliferation kinetics of the tissue of origin, tumor development can be initiated by genetic events, causing either a block in terminal differentiation or/and inappropriate activation of growth stimulatory signaling pathways. The net result in both cases is the generation of a cellular clone capable of infinite expansion if it is not constrained by physical barriers or lack of blood supply. Schmitt and collaborators [94] convincingly showed that in a lymphoid mouse tumor model, an intact senescence pathway appears to be pivotal to the efficacy of cyclophosphamide, and its disruption makes tumor cells highly refractory to the drug. On the other hand, as mentioned, Suv39h1-expressing tumors responded to chemotherapy by inducing senescence. However, Suv39h1-null tumors did not show any senescent response but still maintained the apoptotic response. Suv39h1-null tumors with altered apoptotic response do not respond to therapy.

These results suggest that drug efficacy and tumor formation are not fully independent processes. Until recently, tumor formation and the development of drug resistance were thought to be independent processes. Mutations in factors that regulate tumor-suppressive fail-safe mechanisms, such as apoptosis and senescence, allow transformation. Chemotherapeutic compounds activate a separate set of effector pathways that eliminate malignant clones. Mutations in factors that are involved in these separate pathways inhibit the effect of chemotherapy to induce the effector programs to eliminate the tumors. Consequently, defects in antineoplastic fail-safe programs, even if required to allow for tumor formation, do not interfere with the effector program initiated by therapeutic agents. Nevertheless, preclinical data have provided evidence that key regulators, such as p53, participate in tumor prevention and drug action and that tumor mutations acquired during tumor development also confer chemoresistance [95]. Therefore, the "joint model" [96] proposes a functional overlap between the fail-safe and therapeutic effector programs, such that some of the mutations that allowed transformation can also confer chemoresistance by disabling drug effector programs.

The in vitro observation that DNA-damaging agents not only promote apoptosis but also induce cellular senescence $[97,98]$ indicates that genes that control senescence might 
also determine treatment outcome. Using a MYC-driven mouse lymphoma model, p53 and p16INK4A were recently shown to control drug-induced senescence in vivo [94]. Drug-treated lymphomas with apoptotic defects were forced into senescence, and tumors that resumed growth frequently displayed defects in either p53 or p16INK4A. Importantly, drug-induced senescence was shown to contribute to longterm host survival after cancer therapy, as mice bearing lymphomas that were unable to enter senescence in response to therapy had shorter survival times. Notably, drug-inducible senescence is not a phenomenon that is restricted to a mouse lymphoma model, as tissue specimens taken from human breast tumors after chemotherapy also displayed typical features of cellular senescence [98].

Depending on the initiating oncogene, transformation relies on fail-safe defects that disrupt either apoptosis or senescence. There are a number of reports that druginducible senescence could become detectable only after apoptosis has been disabled [99]. It is conceivable that senescence occurs with much slower kinetics, serving as a "backup" fail-safe program in case the first-line response is corrupted. This is supported by sequential disruption of apoptosis- and senescence-controlling genes during tumor formation and subsequent therapy reported in human cancers $[100,101]$.

\section{Senescence-Based Therapy}

Different chemical agents can induce cellular senescence epigenetically. Treatment of primary cells with $\mathrm{H}_{2} \mathrm{O}_{2}$ or butyrate provokes early senescence [102]. Similar results were obtained after treatment with high doses of radiation and other damaging agents [102]. Interestingly, the treatment of different tumor cell lines with different chemotherapeutic agents, radiation, or differentiating agents induces irreversible growth arrest, with enzymatic and morphologic changes resembling those occurring during replicative senescence. Moderate doses of doxorubicine induced a senescent phenotype in 11 out of 14 tumor cell lines analysed, independently of p53 status [103]. A similar effect has been observed in lines from human tumors treated with cisplatin [104], hydroxyurea [105], and bromodeoxyuridine [106]. In mammary carcinoma cell lines treated in vitro and in vivo with differentiating agents, terminal proliferative arrest with minimal toxicity for normal cells has been observed [107].

The propensity of tumor cells to undergo senescence in response to different kinds of damage induced by commonly used chemotherapeutic treatments was compared on cell lines from different tumor origins [66]. Under equitoxic doses, the strongest induction of a senescent phenotype was observed with DNA-interacting agents (doxorubicin, aphidicolin, and cisplatin), and the weakest effect was observed with microtubule-targeting drugs (Taxol and vincristine). A medium response was observed with ionising radiation, cytarabine, and etoposide. Induction of senescence by the drugs was dose-dependent and correlated with the growth arrest observed in the cultures [102, 105-107]. The drug-induced senescent phenotype in tumor cells was not associated with telomere shortening and was not prevented by the expression of telomerase [108].

Drug-induced senescent phenotypes have been confirmed in vivo ([94] and references therein). A study from Poele et al. [98] revealed the correlation between chemotherapeutic treatment in clinical cancer and the senescence response. In frozen samples from breast tumors treated by neoadjuvant chemotherapy (cyclophosphamide, doxorubicin, and 5-fluoracyl), senescent markers were detected in $41 \%$ of samples from treated tumors. Normal tissue was negative, suggesting that the chemotherapy-induced senescence was a specific response of tumor cells. Interestingly, senescence response was associated with wild-type p53 and the increased expression of p16. Similarly, in treatmentinduced senescence, murine $\mathrm{E} \mu$-myc lymphoma response required wild-type p53 and p16 [94].

The Chk2 kinase is a tumor suppressor and key component of the DNA damage checkpoint response that encompasses cell-cycle arrest, apoptosis, and DNA repair. It has also been shown to have a role in replicative senescence resulting from dysfunctional telomeres. Some of these functions are at least partially exerted through activation of the p53 transcription factor. High-level expression of Chk2 in cells with wild-type p53 led to arrested proliferation with senescent features [109]. These were accompanied by p21 induction, consistent with p53 activation. However, Chk2dependent senescence and p21 transcriptional induction also occurred in p53-defective cells. Small interfering RNAmediated knockdown of p21 in p53-defective cells expressing Chk2 resulted in a decrease in senescent cells. DNAdamage response is also induced by cytokines, such as interferons. Sustained treatment with interferon triggers a p53-dependent senescence program. Interferon-treated cells accumulated gamma-H2AX foci and phosphorylated forms of ATM and CHK2. The DNA-damage-signalling pathway was activated by an increase in reactive oxygen species (ROS) induced by interferon and was inhibited by the antioxidant $\mathrm{N}$-acetyl cysteine. RNA interference against ATM inhibited p53 activity and senescence in response to betainterferon [110]. It seems that p53 activation is the primary response to DNA damage, but its absence does not preclude a response with a senescent phenotype.

Comparable to p53, which functions as a fail-safe mediator of DNA-damage response, the p16 inhibitor has been implicated in both response to DNA-damage and control of stress-induced senescence. Although the molecular mechanism used by p16 to control not only temporary but permanent cell-cycle arrest is unclear, p16 responds to DNA-damage in a delayed manner and appears to be indispensable for the maintenance of cellular senescence $[94,98]$. A synthetic inhibitor of CDK4, possibly mimicking the role of p16, produced a DNA-damage-independent form of senescence in cells lacking p16 expression and inhibited the growth of tumors in mice. Use of siRNAs to inactivate the papilomavirus oncoproteins E6 and E7, which deregulate p53 and pRb, restored cellular senescence in cervical cancer cells. Introduction of E2 protein, a negative regulator of E6 and E7, induced senescence in almost all cervical carcinoma cells tested. The effect of E2 was not accompanied by 
telomere shortening, nor was it prevented by telomerase expression. Induction of senescence by E2 was associated with p53 stabilisation and strong induction of p21, and it was prevented by using $\mathrm{p} 21$ antisenses [111].

Many observations indicate that p53, p21, and p16, which regulate cellular senescence, play an important role in treatment-induced senescence of tumor cells. Since these genes are commonly lost in human tumors, we can expect that most human tumors do not respond by undergoing senescence. However, this is not the case. Chemotherapeutic drugs induced senescence in p53- and p16-defective tumor cell lines [107]. in vivo, 20\% of tumors undergoing senescence after treatment showed p53 mutations [98]. We have been able to induce senescence with several chemotherapeutic drugs in p53-null cells independently of p16 (Moneo and Carnero, unpublished). We have found that the induced senescence correlated with p53-independent p21 induction. Moreover, knockout of p53 or p 21 in HCT116 cells decreased but did not abolish cellular senescence. Hence, p16, p53, and p21 might acts as positive regulators but are not absolutely required for this response. Other related tumor suppressors, such as p63 or p73, could be involved, and their role in druginduced senescence should be explored.

Treatment with 6-anilino-5,8-quinoline quinone, a previously described inhibitor of guanylate cyclase, induced cellular senescence [112]. Microarray analysis revealed that this compound induced the Cdk inhibitor p21WAF1 in a p53-independent manner. Furthermore, p21, though not p53, was required for inhibition of proliferation by the drug. The lack of p53 involvement suggests that this compound acts independently of DNA-damage induction. Growth inhibition was also observed in malignant melanoma and breast cancer cell lines. Functional inactivation of the retinoblastoma tumor-suppressor protein converted 6-anilino-5,8quinolinequinone-induced growth arrest into apoptosis. Tumor cell senescence was also found to be induced by $\mathrm{TGFb}$ and by differentiating agents including retinoids. The induction of senescence has been analyzed in more detail with derivatives of vitamin $\mathrm{A}$, which regulate cell growth and differentiation through their effects on gene expression [113].

A prominent feature of immortal cells is a resistance to oxidative stress. By contrast, primary cells undergo senescence when grown for extended periods in tissue culture or exposed to agents that increase production of reactive oxygen species. It has been also found that enhanced glycolysis enables primary mouse cells to avoid senescence by protecting them from oxidative damage, and that immortal ES cells have intrinsically high levels of glycolysis [49]. siRNA downregulation of PGM, an enzyme regulating glycolytic flux, triggers senescent phenotype recovery in tumor cells. Therefore, regulation of glycolysis and/or ROS production might be interesting approaches to the induction of senescence in tumors.

\section{Telomerase Inhibitors}

Restoration of the limited replicative potential in tumors as an anticancer therapy has been widely examined through the targeting of telomerase activity. Early studies indicated that telomerase activity is absent in somatic tissues and present in most cancers [114]. It was, therefore, reasonable to suggest that inhibition of telomerase activity, with a consequent shortening of telomeres and arrest of cell growth, might be an effective treatment of cancer.

Several different approaches to telomerase inhibition have been adopted to prevent the multiplication of neoplastic cells in culture. These have included treatment of the cells with the alkaloid berberine, transfection with an antisense vector for the human telomerase RNA component, introduction of a catalytically inactive, dominant-negative mutant of human telomerase reverse transcriptase, and lowlevel expression of a mutant-template telomerase RNA. All of the treatments inhibit the multiplication of neoplastic cells in culture, and those tested also inhibit tumor formation in mice. It should, however, be noted that the transfection of neoplastic cells with telomerase-inhibitory vectors was accomplished either in culture before their inoculation into mice or (in the case of the antisense RNA) through daily injections into the growing tumors for 7-14 days. No attempt was made to assess the long-term systemic injection of vectors into mice carrying the tumors, leaving the matter of effects on normal cell function yet to be investigated. Telomere shortening has been observed in the treated tumor cells and correlates with inhibition of their proliferation [115]. The expression of threshold levels of mutanttemplate telomerase RNA decreases cell viability despite the retention of endogenous wild-type telomerase RNA, wild-type telomerase activity, and unaltered stable telomere lengths.

One reported advantage of telomerase inhibition as a cancer chemotherapy was that it was not expected to induce cancer in normal cells, as telomerase activity is closely associated with advanced tumors [114]. Knockout of the gene for the RNA component of telomerase in mice does not, however, prevent either tumor formation or neoplastic transformation of cells cultured from such mice [116, 117]. The incidence of spontaneous malignancies is even higher than that of normal mice [117]. A similarly increased risk of cancer is found in individuals with the inherited syndrome dyskeratosis congenita (DKC) that is caused by a mutation in one of the components of telomerase, such that individuals with DKC are deficient for telomerase activity [118]. This increased incidence of cancer is presumably a result of endto-end fusion of chromosomes destabilized by inadequate capping [119]. There is, therefore, the distinct possibility that systemically introduced inhibition of telomerase in cancer chemotherapy would increase the frequency of chromosome aberration and the risk of secondary cancers in normal tissue, particularly when p53 mutations already exist [120].

The situation became more complicated when it was found that telomerase activity is present in stem cells and dividing transit cells of renewing tissues, and even when cell division is induced in tissues conventionally regarded as quiescent. Thus, it seems likely that all tissues with cells able to divide have either ongoing or potential telomerase activity with a capacity for telomere maintenance during cell division. 
Treatment of cancer by telomerase inhibition is still considered potentially valid for several reasons that might mitigate side effects on normal tissues [121]. One reason is that telomeres are longer in normal tissues than in most cancers, and treatment of tumors can be designed to end before telomere depletion in normal tissues [120]. However, further studies with this approach must be carried out to protect renewing tissues, such as intestine, epidermis, and hematopoietic tissue, in which stem cells and transit cells are constantly dividing at a high rate.

It is expected that telomerase inhibitors will be developed that have far fewer side effects than many of the cancer chemotherapeutic agents that are currently available. Individuals with DKC show features that include abnormalities of the skin and nails and eventual failure of proliferation in the bone marrow, which indicates that telomerase is required for normal proliferative capacity in these somatic tissues. Despite this telomerase deficiency, onset of pancytopaenia in these individuals does not occur until a median age of 10 years, which indicates that it might be relatively safe to administer telomerase inhibitors continuously for several years.

Telomerase inhibitors will not be useful, however, for the minority of tumors that use ALT. In addition, in telomerase-positive tumors it can be predicted that effective telomerase inhibitors will exert an extremely strong selection pressure for the emergence of resistant cells that use the ALT mechanism. Activation of ALT was not observed in cellculture experiments in which telomerase-positive cell lines were treated with small-molecule inhibitors of telomerase or dominant-negative TERT mutants [122], indicating that it is not a high-frequency event. This might be a problem, however, in clinically significant tumors containing as many as $10^{12}$ cells. Development of ALT inhibitors may, therefore, be necessary. For tumors that use both telomere maintenance mechanisms, treatment might need to be initiated with a combination of telomerase and ALT inhibitors. Both telomerase and ALT must access the telomere, but how this might be achieved is at present unknown. A further possibility could be to identify molecular targets for simultaneous inhibition of both telomere maintenance mechanisms, since proteins involved in telomerase-based and ALT-mediated events may overlap.

\section{Concluding Remarks}

The concept of senescence as a barrier to tumorigenesis, either by natural replicative limits or as stress-induced senescence leads to a critical evaluation of the benefits that can be achieved for cancer diagnosis and therapy. It is accepted that neoplastic cells can be forced to undergo senescence by genetic manipulations and by epigenetic factors, including anticancer drugs, radiation, and differentiating agents. These senescent features can be imposed even in the absence of the two functional effector pathways, p53 and pRb. This lead to speculate the possible benefits of inducing an unspecific senescence program to stop tumor growth. This might be of value added to surgery or radiation; however, possible escape from a yet uncontrolled senescent phenotype and the unknown effect in vivo of senescent stromal cells might hamper these efforts. A more controlled induction of senescence through the knowledge of pathways involved and targeting specific targets might rend a less profitable but more valued effort. The use of tools such as oncolytic viruses driven by telomerase promoters might also work better than direct inhibition of the protein. However, it is too early and more research is needed in the basic understanding of the molecular mechanisms driving the senescence processes before embarking patients in such therapy.

\section{Acknowledgments}

This work was supported by Grants from the Spanish Ministry of Science and Innovation (SAF2009-08605) and Consejeria de Salud, Junta de Andalucia (PI-0142). A. Carnero's Lab is also funded by a fellowship from Fundacion Oncologica FERO supported by Fundació Josep Botet.

\section{References}

[1] L. Hayflick, "The limited in vitro lifetime of human diploid cell strains," Experimental Cell Research, vol. 37, no. 3, pp. 614-636, 1965.

[2] D. Hanahan and R. A. Weinberg, "The hallmarks of cancer," Cell, vol. 100, no. 1, pp. 57-70, 2000.

[3] G. Untergasser, H. B. Koch, A. Menssen, and H. Hermeking, "Characterization of epithelial senescence by serial analysis of gene expression: identification of genes potentially involved in prostate cancer," Cancer Research, vol. 62, no. 21, pp. 62556262, 2002.

[4] D. X. Mason, T. J. Jackson, and A. W. Lin, "Molecular signature of oncogenic ras-induced senescence," Oncogene, vol. 23, no. 57, pp. 9238-9246, 2004.

[5] S. R. Schwarze, V. X. Fu, J. A. Desotelle, M. L. Kenowski, and D. F. Jarrard, "The identification of senescence-specific genes during the induction of senescence in prostate cancer cells," Neoplasia, vol. 7, no. 9, pp. 816-823, 2005.

[6] J. W. Shay and I. B. Roninson, "Hallmarks of senescence in carcinogenesis and cancer therapy," Oncogene, vol. 23, no. 16, pp. 2919-2933, 2004.

[7] E. Thomas, E. Al-Baker, S. Dropcova et al., "Different kinetics of senescence in human fibroblasts and peritoneal mesothelial cells," Experimental Cell Research, vol. 236, no. 1, pp. 355-358, 1997.

[8] H. Rubin, "The disparity between human cell senescence in vitro and lifelong replication in vivo," Nature Biotechnology, vol. 20, no. 7, pp. 675-681, 2002.

[9] W. F. Wright and J. W. Shay, "Time, telomeres and tumours: is cellular senescence more than an anticancer mechanism?" Trends in Cell Biology, vol. 5, no. 8, pp. 293-296, 1995.

[10] D. Kipling, D. Wynford-Thomas, C. J. Jones et al., "Telomeredependent senescence," Nature Biotechnology, vol. 17, no. 4, pp. 313-314, 1999.

[11] A. M. Olovnikov, "A theory of marginotomy: the incomplete copying of template margin in enzymic synthesis of polynucleotides and biological significance of the phenomenon," Journal of Theoretical Biology, vol. 41, no. 1, pp. 181-190, 1973. 
[12] L. Ruiz, M. Traskine, I. Ferrer et al., "Characterization of the p53 response to oncogene-induced senescene," PLoS One, vol. 3, no. 9, Article ID e3230, 2008.

[13] F. D'Adda Di Fagagna, "Living on a break: cellular senescence as a DNA-damage response," Nature Reviews Cancer, vol. 8, no. 7, pp. 512-522, 2008.

[14] M. Narita, S. Nũnez, E. Heard et al., "Rb-mediated heterochromatin formation and silencing of E2F target genes during cellular senescence," Cell, vol. 113, no. 6, pp. 703-716, 2003.

[15] J. Campisi, "Senescent cells, tumor suppression, and organismal aging: good citizens, bad neighbors," Cell, vol. 120, no. 4, pp. 513-522, 2005.

[16] P. Castro, D. Giri, D. Lamb, and M. Ittmann, "Cellular senescence in the pathogenesis of benign prostatic hyperplasia," Prostate, vol. 55, no. 1, pp. 30-38, 2003.

[17] C. Michaloglou, L. C. W. Vredeveld, W. J. Mooi, and D. S. Peeper, "BRAF in benign and malignant human tumours," Oncogene, vol. 27, no. 7, pp. 877-895, 2008.

[18] A. Krtolica, S. Parrinello, S. Lockett, P. Y. Desprez, and J. Campisi, "Senescent fibroblasts promote epithelial cell growth and tumorigenesis: a link between cancer and aging," Proceedings of the National Academy of Sciences of the United States of America, vol. 98, no. 21, pp. 12072-12077, 2001.

[19] C. Bavik, I. Coleman, J. P. Dean, B. Knudsen, S. Plymate, and P. S. Nelson, "The gene expression program of prostate fibroblast senescence modulates neoplastic epithelial cell proliferation through paracrine mechanisms," Cancer Research, vol. 66, no. 2, pp. 794-802, 2006.

[20] S. Parrinello, J. P. Coppe, A. Krtolica, and J. Campisi, "Stromal-epithelial interactions in aging and cancer: senescent fibroblasts alter epithelial cell differentiation," Journal of Cell Science, vol. 118, no. 3, pp. 485-496, 2005.

[21] J. P. Coppé, C. K. Patil, F. Rodier et al., "A human-like senescence-associated secretory phenotype is conserved in mouse cells dependent on physiological oxygen," PLoS One, vol. 5, no. 2, Article ID e9188, 2010.

[22] J. P. Coppé, C. K. Patil, F. Rodier et al., "Senescenceassociated secretory phenotypes reveal cell-nonautonomous functions of oncogenic RAS and the p53 tumor suppressor," PLoS Biology, vol. 6, no. 12, pp. 2853-2868, 2008.

[23] J. P. Coppé, P. Y. Desprez, A. Krtolica, and J. Campisi, “The senescence-associated secretory phenotype: the dark side of tumor suppression," Annual Review of Pathology, vol. 5, pp. 99-118, 2010.

[24] A. R. Davalos, J. P. Coppe, J. Campisi, and P. Y. Desprez, "Senescent cells as a source of inflammatory factors for tumor progression," Cancer and Metastasis Reviews, vol. 29, pp. 273283, 2010.

[25] M. Collado and M. Serrano, "The power and the promise of oncogene-induced senescence markers," Nature Reviews Cancer, vol. 6, no. 6, pp. 472-476, 2006.

[26] A. Carnero, W. Link, J. F. Martinez et al., "Cellular senescence and cancer," Advances in Cancer Research, vol. 3, pp. 183-198, 2003.

[27] C. Chandeck and W. J. Mooi, "Oncogene-induced cellular senescence," Advances in Anatomic Pathology, vol. 17, no. 1, pp. 42-48, 2010.

[28] M. Braig and C. A. Schmitt, "Oncogene-induced senescence: putting the brakes on tumor development," Cancer Research, vol. 66, no. 6, pp. 2881-2884, 2006.
[29] S. Courtois-Cox, S. L. Jones, and K. Cichowski, "Many roads lead to oncogene-induced senescence," Oncogene, vol. 27, no. 20, pp. 2801-2809, 2008.

[30] J. Bartek, J. Bartkova, and J. Lukas, "DNA damage signalling guards against activated oncogenes and tumour progression," Oncogene, vol. 26, no. 56, pp. 7773-7779, 2007.

[31] Y. Ruzankina, A. Asare, and E. J. Brown, "Replicative stress, stem cells and aging," Mechanisms of Ageing and Development, vol. 129, no. 7-8, pp. 460-466, 2008.

[32] J. Kenyon and S. L. Gerson, "The role of DNA damage repair in aging of adult stem cells," Nucleic Acids Research, vol. 35, no. 22, pp. 7557-7565, 2007.

[33] R. Di Micco, M. Fumagalli, A. Cicalese et al., "Oncogeneinduced senescence is a DNA damage response triggered by DNA hyper-replication," Nature, vol. 444, no. 7119, pp. 638642, 2006.

[34] J. F. Passos and T. Von Zglinicki, "Oxygen free radicals in cell senescence: are they signal transducers?" Free Radical Research, vol. 40, no. 12, pp. 1277-1283, 2006.

[35] S. Parrinello, E. Samper, A. Krtolica, J. Goldstein, S. Melov, and J. Campisi, "Oxygen sensitivity severely limits the replicative lifespan of murine fibroblasts," Nature Cell Biology, vol. 5, no. 8, pp. 741-747, 2003.

[36] M. Vergel and A. Carnero, "Bypassing cellular senescence by genetic screening tools," Clinical and Translational Oncology, vol. 12, no. 6, pp. 410-417, 2010.

[37] M. Malumbres and A. Carnero, "Cell cycle deregulation: a common motif in cancer," Progress in Cell Cycle Research, vol. 5, pp. 5-18, 2003.

[38] J. R. Smith and O. M. Pereira-Smith, "Replicative senescence: implications for in vivo aging and tumor suppression," Science, vol. 273, no. 5271, pp. 63-67, 1996.

[39] E. L. Duncan, N. J. Whitaker, E. L. Moy, and R. R. Reddel, "Assignment of SV40-immortalized cells to more than one complementation group for immortalization," Experimental Cell Research, vol. 205, no. 2, pp. 337-344, 1993.

[40] J. C. Barrett, L. A. Annab, D. Alcorta, G. Preston, P. Vojta, and Y. Yin, "Cellular senescence and cancer," Cold Spring Harbor Symposia on Quantitative Biology, vol. 59, pp. 411-418, 1994.

[41] M. Serrano and M. A. Blasco, "Putting the stress on senescence," Current Opinion in Cell Biology, vol. 13, no. 6, pp. 748-753, 2001.

[42] C. A. Schmitt, "Cellular senescence and cancer treatment," Biochimica et Biophysica Acta, vol. 1775, no. 1, pp. 5-20, 2007.

[43] W. J. Mooi and D. S. Peeper, "Oncogene-induced cell senescence-halting on the road to cancer," New England Journal of Medicine, vol. 355, no. 10, pp. 1037-1046, 2006.

[44] A. Carnero and M. E. Lleonart, "Epigenetic mechanisms in senescence, immortalisation and cancer," Biological Reviews of the Cambridge Philosophical Society. In press.

[45] M. E. Castro, I. Ferrer, A. Cascón et al., "PPP1CA contributes to the senescence program induced by oncogenic Ras," Carcinogenesis, vol. 29, no. 3, pp. 491-499, 2008.

[46] J. F. Leal, I. Ferrer, C. Blanco-Aparicio et al., "S-adenosylhomocysteine hydrolase downregulation contributes to tumorigenesis," Carcinogenesis, vol. 29, no. 11, pp. 20892095, 2008

[47] M. E. LLeonart, F. Vidal, D. Gallardo et al., "New p53 related genes in human tumors: significant downregulation in colon and lung carcinomas," Oncology Reports, vol. 16, no. 3, pp. 603-608, 2006.

[48] J. F. M. Leal, J. Fominaya, A. Cascón et al., "Cellular senescence bypass screen identifies new putative tumor suppressor genes," Oncogene, vol. 27, no. 14, pp. 1961-1970, 2008. 
[49] H. Kondoh, M. E. Lleonart, J. Gil et al., "Glycolytic enzymes can modulate cellular life span," Cancer Research, vol. 65, no. 1, pp. 177-185, 2005.

[50] A. L. Fridman, R. Rosati, Q. Li, and M. A. Tainsky, "Epigenetic and functional analysis of IGFBP3 and IGFBPrP1 in cellular immortalization," Biochemical and Biophysical Research Communications, vol. 357, no. 3, pp. 785-791, 2007.

[51] R. M. Kortlever and R. Bernards, "Senescence, wound healing and cancer: the PAI-1 connection," Cell Cycle, vol. 5, no. 23, pp. 2697-2703, 2006.

[52] R. M. Kortlever, P. J. Higgins, and R. Bernards, "Plasminogen activator inhibitor- 1 is a critical downstream target of p53 in the induction of replicative senescence," Nature Cell Biology, vol. 8, no. 8, pp. 877-884, 2006.

[53] W. Wang, J. X. Chen, R. Liao et al., "Sequential activation of the MEK-extracellular signal-regulated kinase and MKK3/6p38 mitogen-activated protein kinase pathways mediates oncogenic ras-induced premature senescence," Molecular and Cellular Biology, vol. 22, no. 10, pp. 3389-3403, 2002.

[54] R. Haq, J. D. Brenton, M. Takahashi, D. Finan, R. Rottapel, and B. Zanke, "Constitutive p38HOG mitogen-activated protein kinase activation induces permanent cell cycle arrest and senescence," Cancer Research, vol. 62, no. 17, pp. 50765082, 2002.

[55] H. Zhang and S. N. Cohen, "Smurf2 up-regulation activates telomere-dependent senescence," Genes and Development, vol. 18, no. 24, pp. 3028-3040, 2004.

[56] M. Shibanuma, E. Mochizuki, R. Maniwa et al., "Induction of senescence-like phenotypes by forced expression of hic-5, which encodes a novel LIM motif protein, in immortalized human fibroblasts," Molecular and Cellular Biology, vol. 17, no. 3, pp. 1224-1235, 1997.

[57] J. Campisi and F. D’Adda Di Fagagna, "Cellular senescence: when bad things happen to good cells," Nature Reviews Molecular Cell Biology, vol. 8, no. 9, pp. 729-740, 2007.

[58] D. Wynford-Thomas, "p53: guardian of cellular senescence," Journal of Pathology, vol. 180, no. 2, pp. 118-121, 1996.

[59] J. Bond, M. Haughton, J. Blaydes, V. Gire, D. WynfordThomas, and F. Wyllie, "Evidence that transcriptional activation by $\mathrm{p} 53$ plays a direct role in the induction of cellular senescence," Oncogene, vol. 13, no. 10, pp. 2097-2104, 1996.

[60] L. Chin, S. E. Artandi, Q. Shen et al., "p53 deficiency rescues the adverse effects of telomere loss and cooperates with telomere dysfunction to accelerate carcinogenesis," Cell, vol. 97, no. 4, pp. 527-538, 1999.

[61] M. Ashcroft, Y. Taya, and K. H. Vousden, "Stress signals utilize multiple pathways to stabilize p53," Molecular and Cellular Biology, vol. 20, no. 9, pp. 3224-3233, 2000.

[62] J. P. Blaydes and D. Wynford-Thomas, "The proliferation of normal human fibroblasts is dependent upon negative regulation of 53 function by mdm2," Oncogene, vol. 16, no. 25, pp. 3317-3322, 1998.

[63] T. Kamijo, F. Zindy, M. F. Roussel et al., "Tumor suppression at the mouse INK4a locus mediated by the alternative reading frame product p19(ARF)," Cell, vol. 91, no. 5, pp. 649-659, 1997.

[64] A. Carnero, J. D. Hudson, C. M. Price, and D. H. Beach, "p16(INK4A) and p19(ARF) act in overlapping pathways in cellular immortalization," Nature Cell Biology, vol. 2, no. 3, pp. 148-155, 2000.
[65] A. Carnero and D. H. Beach, "Absence of p21 cooperates with c-myc in bypassing Ras-induced senescence and enhances oncogenic cooperation," Oncogene, vol. 23, no. 35, pp. 60066011, 2004.

[66] C. Pantoja and M. Serrano, "Murine fibroblasts lacking p21 undergo senescence and are resistant to transformation by oncogenic Ras," Oncogene, vol. 18, no. 35, pp. 4974-4982, 1999.

[67] J. P. Brown, W. Wei, and J. M. Sedivy, "Bypass of senescenoe after disruption of $\mathrm{p} 21(\mathrm{CIP} 1) /(\mathrm{WAF} 1)$ gene in normal diploid human fibroblasts," Science, vol. 277, no. 5327, pp. 831-834, 1997.

[68] J. S. L. Ho, W. Ma, D. Y. L. Mao, and S. Benchimol, “p53dependent transcriptional repression of c-myc is required for G cell cycle arrest," Molecular and Cellular Biology, vol. 25, no. 17, pp. 7423-7431, 2005.

[69] D. F. Jarrard, S. Sarkar, Y. Shi et al., "p16/pRb pathway alterations are required for bypassing senescence in human prostate epithelial cells," Cancer Research, vol. 59, no. 12, pp. 2957-2964, 1999.

[70] S. Haferkamp, S. L. Tran, T. M. Becker, L. L. Scurr, R. F. Kefford, and H. Rizos, "The relative contributions of the p53 and pRb pathways in oncogene-induced melanocyte senescence," Aging, vol. 1, no. 6, pp. 542-556, 2009.

[71] X. Ye, B. Zerlanko, R. Zhang et al., "Definition of pRBand p53-dependent and -independent steps in HIRA/ASF1amediated formation of senescence-associated heterochromatin foci," Molecular and Cellular Biology, vol. 27, no. 7, pp. 2452-2465, 2007.

[72] G. Mulligan and T. Jacks, "The retinoblastoma gene family: cousins with overlapping interests," Trends in Genetics, vol. 14, no. 6, pp. 223-229, 1998.

[73] A. Carnero and G. J. Hannon, "The INK4 family of CDK inhibitors," Current Topics in Microbiology and Immunology, vol. 227, pp. 43-56, 1997.

[74] I. Palmero, B. McConnell, D. Parry et al., "Accumulation of p16(INK4a) in mouse fibroblasts as a function of replicative senescence and not of retinoblastoma gene status," Oncogene, vol. 15, no. 5, pp. 495-503, 1997.

[75] A. Okamoto, D. J. Demetrick, E. A. Spillare et al., "p16(INK4)mutations and altered expression in human tumors and cell lines," Cold Spring Harbor Symposia on Quantitative Biology, vol. 59, pp. 49-57, 1994.

[76] P. Krimpenfort, K. C. Quon, W. J. Mooi, A. Loonstra, and A. Berns, "Loss of p16 confers susceptibility to metastatic melanoma in mice," Nature, vol. 413, no. 6851, pp. 83-86, 2001.

[77] N. E. Sharpless, N. Bardeesy, K. H. Lee et al., "Loss of p16 with retention of p19 predisposes mice to tumorigenesis," Nature, vol. 413, no. 6851, pp. 86-91, 2001.

[78] B. Amati, K. Alevizopoulos, and J. Vlach, "Myc and the cell cycle," Frontiers in Bioscience, vol. 3, pp. d250-d268, 1998.

[79] J. Wang, L. Y. Xie, S. Allan, D. Beach, and G. J. Hannon, "Myc activates telomerase," Genes and Development, vol. 12, no. 12, pp. 1769-1774, 1998.

[80] J. Gil, P. Kerai, M. Lleonart et al., "Immortalization of primary human prostate epithelial cells by c-Myc," Cancer Research, vol. 65, no. 6, pp. 2179-2185, 2005.

[81] S. B. Baylin, S. A. Belinsky, and J. G. Herman, "Aberrant methylation of gene promoters in cancer-concepts, misconcepts, and promise," Journal of the National Cancer Institute, vol. 92, no. 18, pp. 1460-1461, 2000. 
[82] T. R. Brummelkamp, K. Berns, E. M. Hijmans et al., "Functional identification of cancer-relevant genes through largescale RNA interference screens in mammalian cells," Cold Spring Harbor Symposia on Quantitative Biology, vol. 69, pp. 439-445, 2004.

[83] C. Michaloglou, L. C. W. Vredeveld, M. S. Soengas et al., "BRAF-associated senescence-like cell cycle arrest of human naevi," Nature, vol. 436, no. 7051, pp. 720-724, 2005.

[84] M. Collado, J. Gil, A. Efeyan et al., "Tumour biology: senescence in premalignant tumours," Nature, vol. 436, no. 7051, p. 642, 2005.

[85] E. L. Denchi, C. Attwooll, D. Pasini, and K. Helin, "Deregulated E2F activity induces hyperplasia and senescence-like features in the mouse pituitary gland," Molecular and Cellular Biology, vol. 25, no. 7, pp. 2660-2672, 2005.

[86] Z. Chen, L. C. Trotman, D. Shaffer et al., "Crucial role of p53-dependent cellular senescence in suppression of Ptendeficient tumorigenesis," Nature, vol. 436, no. 7051, pp. 725730, 2005.

[87] M. Braig, S. Lee, C. Loddenkemper et al., "Oncogeneinduced senescence as an initial barrier in lymphoma development," Nature, vol. 436, no. 7051, pp. 660-665, 2005.

[88] I. B. Roninson, "Tumor cell senescence in cancer treatment," Cancer Research, vol. 63, no. 11, pp. 2705-2715, 2003.

[89] O. M. Pereira-Smith and J. R. Smith, "Genetic analysis of indefinite division in human cells: identification of four complementation groups," Proceedings of the National Academy of Sciences of the United States of America, vol. 85, no. 16, pp. 6042-6046, 1988.

[90] B. B. McConnell, M. Starborg, S. Brookes, and G. Peters, "Inhibitors of cyclin-dependent kinases induce features of replicative senescence in early passage human diploid fibroblasts," Current Biology, vol. 8, no. 6, pp. 351-354, 1998.

[91] A. Carnero, J. D. Hudson, G. J. Hannon, and D. H. Beach, "Loss-of-function genetics in mammalian cells: the p53 tumor suppressor model," Nucleic Acids Research, vol. 28, no. 11, pp. 2234-2241, 2000.

[92] A. Carnero, "Targeting the cell cycle for cancer therapy," British Journal of Cancer, vol. 87, no. 2, pp. 129-133, 2002.

[93] K. L. Ball, S. Lain, R. Fåhraeus, C. Smythe, and D. P. Lane, "Cell-cycle arrest and inhibition of Cdk4 activity by small peptides based on the carboxy-terminal domain of p21(WAF1)," Current Biology, vol. 7, no. 1, pp. 71-80, 1997.

[94] C. A. Schmitt, J. S. Fridman, M. Yang et al., "A senescence program controlled by $\mathrm{p} 53$ and p16 contributes to the outcome of cancer therapy," Cell, vol. 109, no. 3, pp. 335-346, 2002.

[95] S. W. Lowe, H. E. Ruley, T. Jacks, and D. E. Housman, "p53-Dependent apoptosis modulates the cytotoxicity of anticancer agents," Cell, vol. 74, no. 6, pp. 957-967, 1993.

[96] S. W. Lowe, E. Cepero, and G. Evan, "Intrinsic tumour suppression,” Nature, vol. 432, no. 7015, pp. 307-315, 2004.

[97] I. B. Roninson, "Tumor senescence as a determinant of drug response in vivo," Drug Resistance Updates, vol. 5, no. 5, pp. 204-208, 2002.

[98] R. H. te Poele, A. L. Okorokov, L. Jardine, J. Cummings, and S. P. Joel, "DNA damage is able to induce senescence in tumor cells in vitro and in vivo," Cancer Research, vol. 62, no. 6, pp. 1876-1883, 2002.

[99] K. W. Maloney, L. McGavran, L. F. Odom, and S. P. Hunger, "Acquisition of p16(INK4A) and p15(INK4B) gene abnormalities between initial diagnosis and relapse in children with acute lymphoblastic leukemia," Blood, vol. 93, no. 7, pp. 2380-2385, 1999.
[100] T. L. Carter, P. M. Watt, R. Kumar et al., "Hemizygous p16 deletion in pediatric acute lymphoblastic leukemia predicts independent risk of relapse," Blood, vol. 97, no. 2, pp. 572$574,2001$.

[101] K. S. J. Elenitoba-Johnson, R. D. Gascoyne, M. S. Lim, M. Chhanabai, E. S. Jaffe, and M. Raffeld, "Homozygous deletions at chromosome 9p21 involving p16 and p15 are associated with histologic progression in follicle center lymphoma," Blood, vol. 91, no. 12, pp. 4677-4685, 1998.

[102] Q. M. Chen, "Replicative senescence and oxidant-induced premature senescence. Beyond the control of cell cycle checkpoints," Annals of the New York Academy of Sciences, vol. 908, pp. 111-125, 2000.

[103] B.-D. Chang, E. V. Broude, M. Dokmanovic et al., "A senescence-like phenotype distinguishes tumor cells that undergo terminal proliferation arrest after exposure to anticancer agents," Cancer Research, vol. 59, no. 15, pp. 37613767, 1999.

[104] X. Wang, S. C. H. Wong, J. Pan et al., "Evidence of cisplatininduced senescent-like growth arrest in nasopharyngeal carcinoma cells," Cancer Research, vol. 58, no. 22, pp. 50195022, 1998.

[105] E. J. Yeo, Y. C. Hwang, C. M. Kang et al., "Senescencelike changes induced by hydroxyurea in human diploid fibroblasts," Experimental Gerontology, vol. 35, no. 5, pp. 553$571,2000$.

[106] E. Michishita, K. Nakabayashi, T. Suzuki et al., "5Bromodeoxyuridine induces senescence-like phenomena in mammalian cells regardless of cell type or species," Journal of Biochemistry, vol. 126, no. 6, pp. 1052-1059, 1999.

[107] B. D. Chang, Y. Xuan, E. V. Broude et al., "Role of p53 and p21(waf1/cip1) in senescence-like terminal proliferation arrest induced in human tumor cells by chemotherapeutic drugs," Oncogene, vol. 18, no. 34, pp. 4808-4818, 1999.

[108] L. W. Elmore, C. W. Rehder, X. Di et al., "Adriamycininduced senescence in breast tumor cells involves functional p53 and telomere dysfunction," Journal of Biological Chemistry, vol. 277, no. 38, pp. 35509-35515, 2002.

[109] V. Gire, P. Roux, D. Wynford-Thomas, J. M. Brondello, and V. Dulic, "DNA damage checkpoint kinase Chk2 triggers replicative senescence," EMBO Journal, vol. 23, no. 13, pp. 2554-2563, 2004.

[110] O. Moiseeva, F. A. Mallette, U. K. Mukhopadhyay, A. Moores, and G. Ferbeyre, "DNA damage signaling and p53dependent senescence after prolonged $\beta$-interferon stimulation," Molecular Biology of the Cell, vol. 17, no. 4, pp. 15831592, 2006.

[111] S. I. Wells, D. A. Francis, A. Y. Karpova, J. J. Dowhanick, J. D. Benson, and P. M. Howley, "Papillomavirus E2 induces senescence in HPV-positive cells via pRB- and p21(CIP)dependent pathways," EMBO Journal, vol. 19, no. 21, pp. 5762-5771, 2000.

[112] D. Lodygin, A. Menssen, and H. Hermeking, "Induction of the Cdk inhibitor p21 by LY83583 inhibits tumor cell proliferation in a p53-independent manner," Journal of Clinical Investigation, vol. 110, no. 11, pp. 1717-1727, 2002.

[113] I. B. Roninson and M. Dokmanovic, "Induction of senescence-associated growth inhibitors in the tumorsuppressive function of retinoids," Journal of Cellular Biochemistry, vol. 88, no. 1, pp. 83-94, 2003. 
[114] N. W. Kim, M. A. Piatyszek, K. R. Prowse et al., "Specific association of human telomerase activity with immortal cells and cancer," Science, vol. 266, no. 5193, pp. 2011-2015, 1994.

[115] W. C. Hahn, S. A. Stewart, M. W. Brooks et al., "Inhibition of telomerase limits the growth of human cancer cells," Nature Medicine, vol. 5, no. 10, pp. 1164-1170, 1999.

[116] M. A. Blasco, H. W. Lee, M. P. Hande et al., "Telomere shortening and tumor formation by mouse cells lacking telomerase RNA," Cell, vol. 91, no. 1, pp. 25-34, 1997.

[117] K. L. Rudolph, S. Chang, H. W. Lee et al., "Longevity, stress response, and cancer in aging telomerase-deficient mice," Cell, vol. 96, no. 5, pp. 701-712, 1999.

[118] T. J. Vulliamy, A. Marrone, S. W. Knight, A. Walne, P. J. Mason, and I. Dokal, "Mutations in dyskeratosis congenita: their impact on telomere length and the diversity of clinical presentation," Blood, vol. 107, no. 7, pp. 2680-2685, 2006.

[119] R. Marciniak and L. Guarente, "Human genetics: testing telomerase," Nature, vol. 413, no. 6854, pp. 370-373, 2001.

[120] S. E. Artandi and R. A. DePinho, "Mice without telomerase: what can they teach us about human cancer?" Nature Medicine, vol. 6, no. 8, pp. 852-855, 2000.

[121] S. E. Holt, W. E. Wright, and J. W. Shay, "Multiple pathways for the regulation of telomerase activity," European Journal of Cancer A, vol. 33, no. 5, pp. 761-766, 1997.

[122] X. Zhang, V. Mar, W. Zhou, L. Harrington, and M. O. Robinson, "Telomere shortening and apoptosis in telomeraseinhibited human tumor cells," Genes and Development, vol. 13, no. 18 , pp. 2388-2399, 1999. 


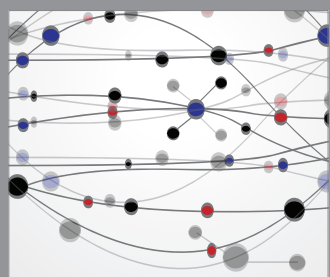

The Scientific World Journal
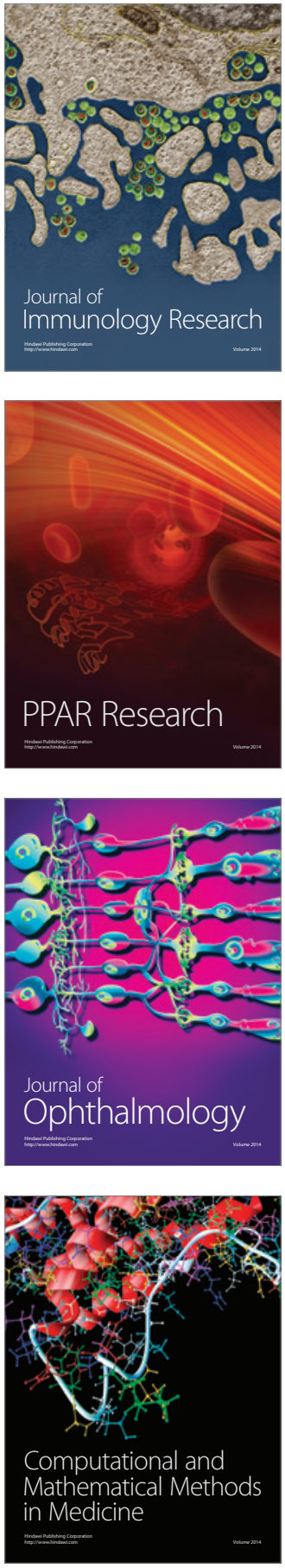

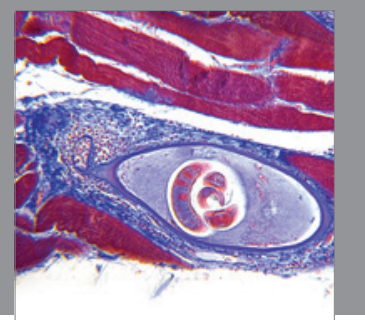

Gastroenterology

Research and Practice
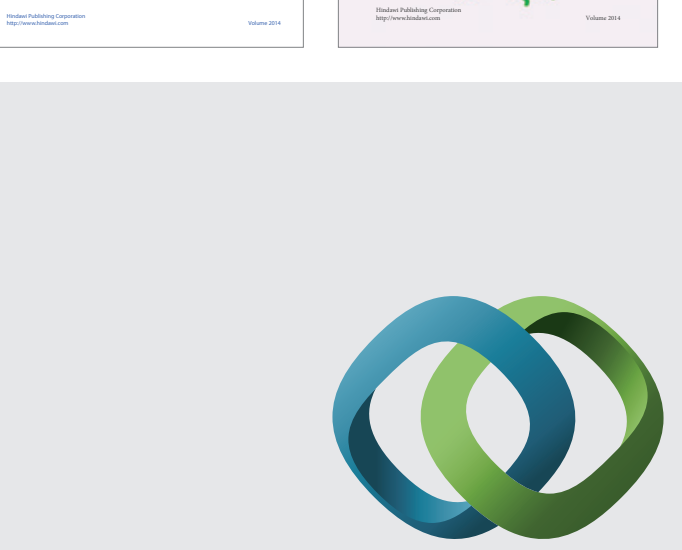

\section{Hindawi}

Submit your manuscripts at

http://www.hindawi.com
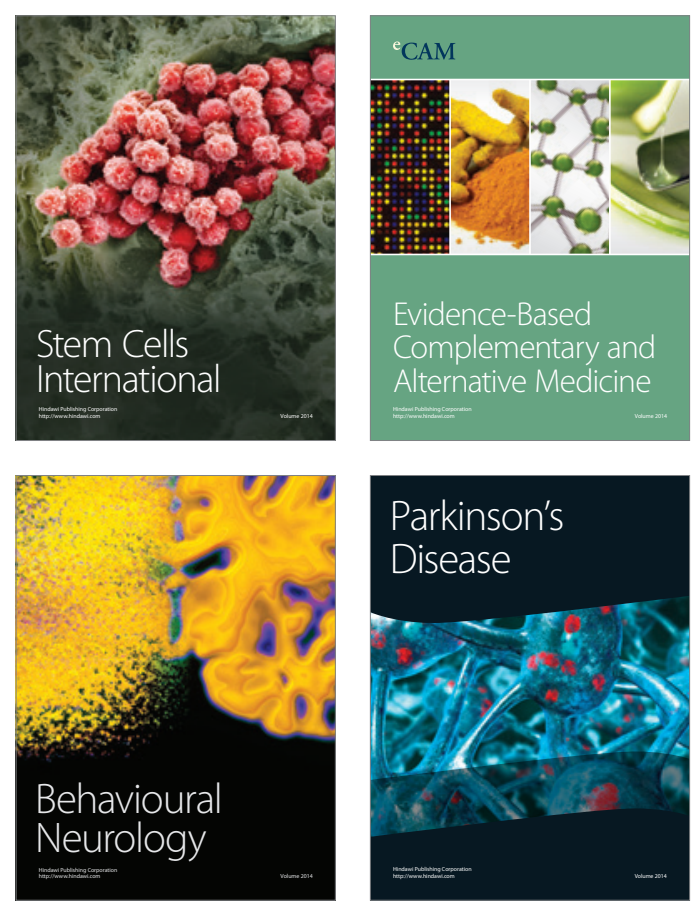

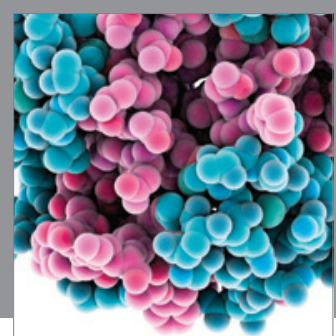

Journal of
Diabetes Research

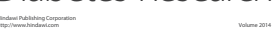

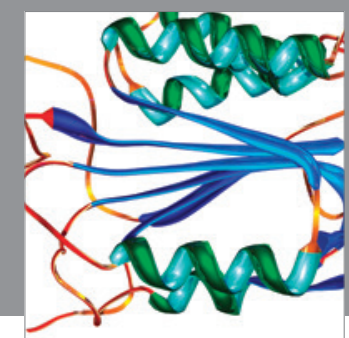

Disease Markers
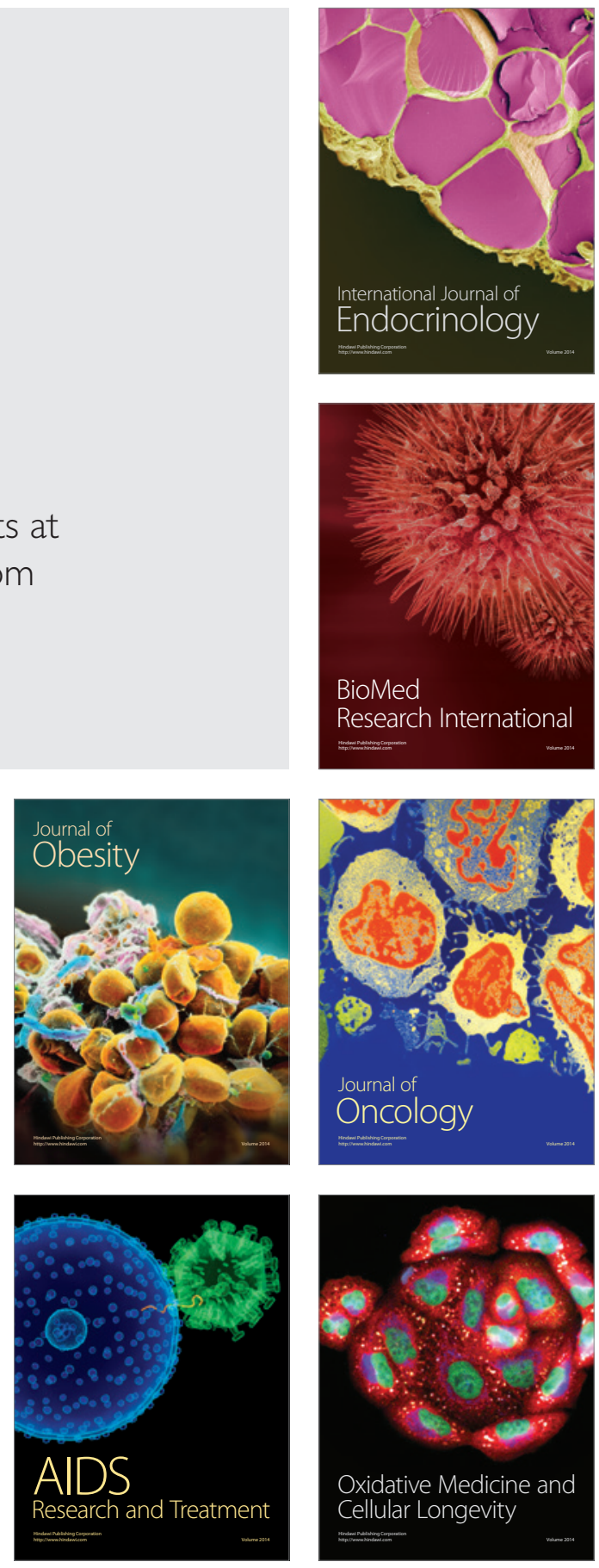